\title{
PENGARUH BRAND IMAGE, ELECTRONIC WORD OF MOUTH (eWOM) DAN CUSTOMER SATISFACTION TERHADAP PURCHASE INTENTION
}

\author{
Annastasya \\ Program Studi Magister Manajemen Universitas Tarumanagara \\ annastasyachen@gmail.com
}

Masuk : 07-12-2020, revisi : 24-12-2020, diterima untuk diterbitkan : 28-12-2020

\begin{abstract}
This research wants to show the influence of brand image, electronic word of mouth (eWOM), and customer satisfaction on purchase intention. This descriptive research involved quantitative data collecting using a questionnaire as a data collection method. The researcher used the convenience sampling method to take 123 respondents with valid data. The data analysis technique used Partial Least Square - Structured Equation Modelling (PLS-SEM) with the help of Smart PLS 3.3.2 software. This study concluded that 1) Brand image has an insignificantly positive effect on purchase intention, 2) Customer Satisfaction has a significantly positive effect on purchase intention, 3) eWOM has a significant positive effect on purchase intention.
\end{abstract}

Keywords: Brand Image, Electronic Word of Mouth, Customer Satisfaction, Purchase Intention

Abstrak: Penelitian ini dibuat untuk menunjukkan pengaruh brand image, electronic word of
mouth (eWOM), dan customer satisfaction terhadap purchase intention. Pada penelitian
deskriptif ini menggunakan pengumpulan data kuantitatif dengan kuesioner secara cross-
sectional sebagai metode pengumpulan data. Metode yang digunakan adalah convenience
sampling dengan sebanyak 123 responden data yang valid. Teknik analisis data menggunakan
Partial Least Square - Structured Equation Modelling (PLS-SEM) dengan bantuan software
Smart PLS 3.3.2. Kesimpulan pada penelitian ini adalah 1) Brand image berpengaruh positif
tidak signifikan terhadap purchase intention, 2) Customer Satisfaction berpengaruh positif
signifikan terhadap purchase intention, 3) eWOM berpengaruh positif signifikan terhadap
purchase intention.

Kata Kunci: Brand Image, Electronic Word of Mouth, Customer Satisfaction, Purchase Intention

\section{PENDAHULUAN}

Bertambahnya jumlah pengguna internet di seluruh dunia konsumen dapat memperoleh sumber informasi produk secara online dari produk yang diinginkan. Menurut Hennig-Thurau et al. (2004), eWOM merupakan pernyataan positif atau negatif yang dibuat oleh konsumen potensial, konsumen riil, atau konsumen yang sebelumnya sudah pernah menggunakan produk tentang sebuah produk, atau perusahaan yang dapat diakses oleh banyak orang atau institusi melalui internet. Lebih lanjut, hasil penelitian Hennig-Thurau et al. (2004) menunjukkan eWOM dapat mempengaruhi purchase intention secara positif. Hasil penelitian ini diperkuat oleh penelitian Susanto dan Keni (2019) yang menyatakan eWOM secara signifikan mempengaruhi purchase intention.

eWOM dikatakan sebagai suatu iklan gratis yang memiliki efektifitas yang baik karena pemasaran yang bersifat tradisional sudah mulai kehilangan efektifitasnya. Farzin dan Fattahi (2018) mengatakan bahwa pada perubahan dari WOM menjadi $e W O M$, telah menjadi faktor yang penting dalam mempengaruhi proses pembentukan perilaku pembelian konsumen. Karena perilaku konsumen $e W O M$ sudah menjadi salah satu faktor penting dalam membentuk perilaku konsumen dalam pengambilan keputusan pembelian bagi konsumen. 
Faktor lain yang mempengaruhinya adalah kepuasan pelanggan yang dapat juga diartikan sebagai keseluruhan sikap yang ditampilkan pelanggan berdasarkan perasaan yang dirasakan saat pelanggan mendapatkan produk atau jasa yang sesuai dengan harapan pelanggan (Swari \& Giantari, 2017). Menurut de Ruyter dan Bloemer (1999), kepuasan konsumen akan memengaruhi niat pembelian. Kepuasan konsumen mengaitkan antara kualitas layanan dan niat pembelian. Kepuasan konsumen yang tinggi maka akan mendorong niat untuk melakukan pembelian produk.

Lien et al. (2015) menyatakan bahwa brand image secara positif memengaruhi purchase intention, dan didukung oleh penelitian dari Hakim dan Keni (2020) dari penelitian mereka menyatakan brand image adalah yang paling berpengaruh kepada purchase intention. Hal ini menunjukan bahwa semakin tinggi tingkat keterlibatan terhadap brand image, maka tingkat keterlibatan terhadap purchase intention akan semakin kuat.

Berdasarkan latar belakang tersebut, tujuan dari penelitian ini adalah untuk meneliti pengaruh brand image, customer satisfaction, dan electronic word of mouth (eWOM) terhadap purchase intention.

\section{TELAAH KEPUSTAKAAN \\ Brand Image}

Alwi dan Kitchen (2014) menjelaskan brand image adalah fenomena subyektif, persepsi yang dibentuk melalui interpretasi rasional dan emosional. Sebuah fenomena yang bersifat subjektif, persepsi terbentuk melalui tingkat rasional dan interpretasi emosional. Berdasarkan penjelasan yang ada di atas maka peneliti dapat menyimpulkan bahwa brand image merupakan persepsi dalam memori konsumen yang terbentuk melalui tingkat rasional dan interpretasi emosial terhadap merek dan penawaran yang diberikan oleh perusahaan.

\section{Customer Satisfaction}

Menurut Kotler dan Keller (2016, p. 235), kepuasan merupakan perasaan senang atau bahagia yang tercipta setelah menggunakan suatu layanan atau produk sesuai dengan yang diharapkan. Maka dapat disimpulkan bahwa kepuasan konsumen dapat diartikan sebagai tanggapan konsumen setelah membandingkan kinerja layanan atau produk antara harapan dengan kenyataan yang ada.

\section{Electronic Word of Mouth (eWOM)}

Abubakar dan Ilkan (2016) berpendapat bahwa "Electronic word-of-mouth (eWOM) consists of review from various people in different social classes, location and with limited social ties." Dapat disimpulkan electronic word of mouth adalah aspek penting pada ekspresi konsumen terhadap merek dalam bentuk tanggapan terhadap sebuah produk atau pelayanan melalui teknologi digital berbasis internet.

\section{Purchase Intention}

Garg dan Joshi (2018) menyatakan "purchase intention refers to the mental stage in the decision-making process where the consumer has developed an actual willingness to act toward an object or brand." Kesimpulannya purchase intention adalah bentuk dari perilaku seorang konsumen yang bersedia melakukan pembelian terhadap suatu produk yang didasari dengan pengalaman, keinginan dan penggunaan terhadap produk.

\section{Kaitan antar Variabel}

\section{Kaitan antara Brand Image dan Purchase Intention}

Lien et al. (2015) menyatakan bahwa brand image secara positif memengaruhi purchase intention. Menurut penelitian Hakim dan Keni (2020), brand image adalah yang paling berpengaruh kepada purchase intention. Berdasarkan uraian tersebut, hipotesis penelitian $\left(\mathrm{H}_{1}\right)$ adalah:

$\mathrm{H}_{1}$ : Brand Image memiliki pengaruh positif terhadap Purchase Intention 


\section{Kaitan antara Customer Satisfaction dan Purchase Intention}

Chu dan Zhang (2016) menyatakan kepuasan konsumen mempunyai pengaruh yang positif dan signifikan terhadap minat pembelian. Menurut de Ruyter dan Bloemer (1999), kepuasan konsumen akan memengaruhi niat pembelian. Berdasarkan uraian tersebut, hipotesis penelitian $\left(\mathrm{H}_{2}\right)$ adalah:

$\mathrm{H}_{2}$ : Customer Satisfaction memiliki pengaruh postif terhadap Purchase Intention

\section{Kaitan antara Electronic Word of Mouth dan Purchase Intention}

Abubakar dan Ilkan (2016) menjelaskan bahwa eWOM memiliki keterkaitan secara positif terhadap purchase intention. Susanto dan Keni (2019) menyatakan eWOM berpengaruh positif terhadap purchase intention. Mortazavi et al. (2014) juga menyatakan dukungan yang sama. Berdasarkan uraian tersebut, hipotesis penelitian $\left(\mathrm{H}_{3}\right)$ adalah:

$\mathrm{H}_{3}$ : Customer Satisfaction memiliki pengaruh positif terhadap Purchase Intention

\section{METODOLOGI PENELITIAN}

\section{Populasi dan Metode Pengambilan Sampel}

Penelitian deskriptif ini melakukan pengumpulan data secara cross-sectional dengan sumber data primer. Metode pengambilan sampel menggunakan non-probability sampling secara convenience sampling terhadap sebanyak 123 responden pengguna Instagram. Berdasarkan data yang terkumpul, responden yang didapati mayoritas berada dalam golongan umur 17-24 tahun yaitu sebesar 43,1\% dan mayoritas merupakan pelajar/mahasiswa, yakni sebesar $45,5 \%$.

\section{Variabel dan Pengukuran}

Penelitian ini memiliki 3 buah variabel independen (Brand Image, Customer Satisfaction, dan Electronic Word of Mouth (eWOM)) dan 1 variabel dependen (Purchase Intention). Untuk mengukur validitas dan reliabilitas dari variabel ini, digunakan beberapa instrumen yang di adaptasi dari studi penelitian terdahulu. Berikut ini adalah tabel yang menunjukkan pengukuran setiap variabel dan sumber yang dipilih:

\section{Tabel 1}

Variabel dan Pengukuran

\begin{tabular}{|c|c|c|}
\hline Variabel & Item & Sumber \\
\hline \multicolumn{3}{|c|}{ Variabel Independen } \\
\hline Brand Image & 4 & Lien et al. (2015) \\
\hline Customer Satisfaction & 6 & Wang et al. (2004); Chae et al. (2002) \\
\hline Electronic Word of Mouth & 8 & Abubakar dan Ilkan (2016); Mortazavi et al. (2014) \\
\hline \multicolumn{3}{|r|}{ Variabel Dependen } \\
\hline Purchase Intention & 5 & Putri et al. (2016); Setiawan dan Rabuani (2019) \\
\hline
\end{tabular}

\section{Metode Analisis Data}

Penganalisisan untuk data yang diperoleh menggunakan Partial Least Square Structured Equation Modelling (PLS-SEM) dengan bantuan software Smart PLS 3.3.2. Analisis data ini dilakukan dengan tiga tahap, yaitu analisis outer model, analisis inner model dan pengujian hipotesis.

\section{HASIL PENELITIAN DAN PEMBAHASAN}

Dalam menguji validitas dilakukan uji Average Variance Extracted (AVE). Nilai AVE dari masing-masing variabel dalam penelitian ini memenuhi syarat validitas dikarenakan nilai AVE yang dihasilkan >0,5. Uji selanjutnya adalah uji reliabilitas, dengan melihat nilai Cronbach's Alpha dan Composite Reliability, dimana dalam penelitian ini masing-masing variabel diperoleh angka $>0,7$ sehingga instrumen penelitian yang digunakan memenuhi syarat reliabilitas.

Selanjutnya, berikut ini adalah tabel yang menunjukkan hasil uji path coefficient yang menunjukkan arah hubungan antar variabel: 
Tabel 2

Hasil Uji Path Coefficient

\begin{tabular}{|l|c|c|}
\hline \multicolumn{1}{|c|}{ Path } & Path Coefficient & Keterangan \\
\hline Brand Image $\rightarrow$ Purchase Intention & 0,051 & Positif \\
\hline Customer Satisfaction $\rightarrow$ Purchase Intention & 0,547 & Positif \\
\hline EWOM $\rightarrow$ Purchase Intention & 0,369 & Positif \\
\hline
\end{tabular}

Brand Image, Customer Satisfaction, dan eWOM memiliki kontribusi terhadap Purchase Intention ke arah yang positif. Berdasarkan angka tersebut, variabel Customer Satisfaction menjadi prediktor terbesar dalam memberikan kontribusi terhadap perubahan naik turunnya variabel Purchase Intention. Sedangkan Brand Image mempunyai nilai path coefficient terendah terhadap Purchase Intention.

\section{Tabel 3}

Uji t dan Uji Signifikansi

\begin{tabular}{|l|c|c|c|c|}
\hline & Path Coefficient & t-statistics & p-value & Keterangan \\
\hline Brand Image $\rightarrow$ Purchase Intention & 0,051 & 0,471 & 0,638 & Ditolak \\
\hline Customer Satisfaction $\rightarrow$ Purchase Intention & 0,547 & 5,098 & 0,000 & Tidak Ditolak \\
\hline EWOM $\rightarrow$ Purchase Intention & 0,369 & 4,828 & 0,000 & Tidak Ditolak \\
\hline
\end{tabular}

Pengujian hipotesis dilakukan dengan uji-t dan uji signifikansi yang dapat terlihat pada tabel 3. Berdasarkan hasil pengujian hipotesis, maka dapat disimpulkan hipotesis $\mathrm{H}_{1}$ ini tidak sesuai dengan penelitian yang dilakukan Lien et al. (2015) yang menunjukkan brand image dapat meningkatkan purchase intention. Penelitian ini juga tidak sesuai dengan penelitian Hakim dan Keni (2020) yang menyatakan brand image adalah yang paling berpengaruh kepada purchase intention. Perbedaan ini dikarenakan dalam meningkatkan purchase intention, masyarakat atau mayoritas responden lebih tertarik dengan ulasan yang ada oleh konsumen sebagai bentuk tanggapan atau pemikiran orang lain terhadap sebuah brand. Selain ulasan, pengaruh yang paling besar dalam penelitian ini adalah kepuasan konsumen dimana tingginya minat pembelian konsumen dipengaruhi oleh pelayanan yang diberikan terhadap konsumen berdasarkan respon dari mayoritas responden.

Pada hipotesis kedua, terdapat hasil pengujian yang menunjukkan bahwa customer satisfaction berpengaruh signifikan positif terhadap purchase intention, sehingga dapat disimpulkan hipotesis $\mathrm{H}_{2}$ tidak ditolak. Hasil penelitian ini sejalan dengan penelitian yang dilakukan oleh Wang et al. (2004) yang meneliti mengenai pengaruh customer satisfaction terhadap keputusan pembelian. Adapun penelitian lain dari Chae et al. (2002) juga mendapatkan hasil penelitian bahwa customer satisfaction memiliki pengaruh yang signifikan dan positif terhadap purchase intention, dimana semakin positif customer satisfaction maka semakin meningkatkan purchase intention. Pada penelitian ini, customer satisfaction memiliki pengaruh yang besar terhadap purchase intention. Kepuasan pelanggan disini terdiri dari indikator pelayanan yang diberikan, serta adanya pengaruh kepuasan emosional terhadap suatu brand.

Terakhir, hasil pengujian hipotesis ketiga menunjukkan bahwa electronic word of mouth (eWOM) berpengaruh signifikan positif terhadap purchase intention. Hasil ini sesuai dengan penelitian yang dilakukan oleh Abubakar dan Ilkan (2016) yang menunjukkan eWOM berpengaruh signifikan dan positif terhadap purchase intention. Penelitian ini juga sejalan dengan penelitian yang dilakukan oleh Mortazavi et al. (2014) bahwa electronic word of mouth berpengaruh positif terhadap purchase intention. Penelitian ini memperoleh hasil yang menunjukkan bahwa ulasan yang positif dari masyarakat terhadap sebuah brand akan memberikan dampak positif pada niat untuk melakukan pembelian. Dapat ditarik kesimpulan, minat untuk melakukan pembelian akan terbentuk dengan adanya ulasan positif masyarakat terhadap sebuah brand. 


\section{KESIMPULAN DAN SARAN}

Dapat ditarik kesimpulan dari hasil penelitian ini, yaitu pertama, variabel brand image berpengaruh secara positif namun tidak signifikan terhadap brand awareness. Hasil penelitian yang kedua menunjukkan variabel customer satisfaction berpengaruh positif dan signifikan terhadap purchase intention. Hasil penelitian yang terakhir, electronic word of mouth (eWOM) juga berpengaruh positif dan signifikan terhadap purchase intention.

\section{IMPLIKASI MANAJERIAL}

Dari hasil tersebut peneliti memberikan saran agar perusahaan dapat lebih berfokus terhadap faktor eWOM dan customer satisfaction. Mayoritas responden sudah cukup puas dengan keamanan dan kemudahan dalam proses pemilihan produk dan bertransaksi. Hal ini berpengaruh pada peningkatan minat pembelian. Perusahaan disarankan untuk lebih baik lagi dalam memberikan pelayanan khususnya customer service dan dalam melakukan transaksi. Hal ini banyak berpengaruh terhadap proses refund yang tergolong lama menurut mayoritas responden sehingga kepuasan pelanggan menjadi menurun. Sama halnya dengan feedback pada ulasan yang saling memengaruhi terhadap niat pembelian pada konsumen

Hal ini bukan berarti perusahaan melupakan faktor brand image untuk meningkatkan purchase intention, sebaliknya perusahaan harus tetap mempertahankan citra perusahaan yang baik agar masyarakat memiliki pandangan yang positif terhadap perusahaan untuk menggiring masyarakat dalam memberikan ulasan yang positif dan meningkatnya rasa kepuasan emosional sehingga meningkatkan niat pembelian di masyarakat.

\section{DAFTAR PUSTAKA}

Abubakar, A. M., \& Ilkan, M. (2016). Impact of online WOM on destination trust and intention to travel: A medical tourism perspective. Journal of Destination Marketing and Management, 5(3), 192-201. https://doi.org/10.1016/j.jdmm.2015.12.005

Alwi, S. F. S., \& Kitchen, P. J. (2014). Projecting corporate brand image and behavioral response in business schools: Cognitive or affective brand attributes? Journal of Business Research, 67(11), 2324-2336. https://doi.org/10.1016/j.jbusres.2014.06.020

Chae, M., Kim, J., Kim, H., \& Ryu, H. (2002). Information quality for mobile internet services: A theoretical model with empirical validation. Electronic Markets, 12(1), 38 46. https://doi.org/10.1080/101967802753433254

Chu, F., \& Zhang, X. (2016). Satisfaction, trust and online purchase intention: A study of consumer perceptions. 2016 International Conference on Logistics, Informatics and Service Sciences, LISS 2016. https://doi.org/10.1109/LISS.2016.7854436

de Ruyter, K., \& Bloemer, J. (1999). Customer loyalty in extended service settings: The interaction between satisfaction, value attainment and positive mood. International Journal of Service Industry Management, 10(3), 320-336. https://doi.org/10.1108/09564239910276917

Farzin, M., \& Fattahi, M. (2018). eWOM through social networking sites and impact on purchase intention and brand image in Iran. Journal of Advances in Management Research, 15(2), 161-183. https://doi.org/10.1108/JAMR-05-2017-0062

Garg, P., \& Joshi, R. (2018). Purchase intention of "Halal" brands in India: The mediating effect of attitude. Journal of Islamic Marketing, 9(3), 683-694. https://doi.org/10.1108/JIMA-11-2017-0125

Hakim, L. L., \& Keni. (2020). Pengaruh brand awareness, brand image dan customer perceived value terhadap purchase intention. Jurnal Manajemen Bisnis Dan Kewirausahaan, 4(3), 81-86. https://doi.org/10.24912/jmbk.v4i3.7921 
Hennig-Thurau, T., Gwinner, K. P., Walsh, G., \& Gremler, D. D. (2004). Electronic word-ofmouth via consumer-opinion platforms: What motivates consumers to articulate themselves on the Internet? Journal of Interactive Marketing, 18(1), 38-52. https://doi.org/10.1002/dir.10073

Kotler, P., \& Keller, K. L. (2016). Marketing management (15th ed.). Pearson Education, Inc.

Lien, C. H., Wen, M. J., Huang, L. C., \& Wu, K. L. (2015). Online hotel booking: The effects of brand image, price, trust and value on purchase intentions. Asia Pacific Management Review, 20(4), 210-218. https://doi.org/10.1016/j.apmrv.2015.03.005

Mortazavi, M., Esfidani, M. R., \& Barzoki, A. S. (2014). Influencing VSN users' purchase intentions: The roles of flow, trust and eWOM. Journal of Research in Interactive Marketing, 8(2), 102-123. https://doi.org/10.1108/JRIM-08-2013-0057

Putri, N., Rachmawati, I., \& Prabowo, F. S. A. (2016). Pengaruh electronic word of mouth terhadap brand equity Indomie (Studi pada followers official account jejaring sosial Indomie). E-Proceeding of Management, 3(3), 2976-2984.

https://openlibrarypublications.telkomuniversity.ac.id/index.php/management/article/vie w/2984/2830

Setiawan, B., \& Rabuani, C. C. (2019). Pengaruh iklan dan endorser terhadap brand awareness serta dampaknya pada keputusan pembelian. Riset, 1(1), 001-015. https://doi.org/10.35212/277621

Susanto, W. K., \& Keni. (2019). Pengaruh social network marketing (SNM) dan electronic word of mouth (eWOM) terhadap minat beli pelanggan. Jurnal Manajemen Bisnis Dan Kewirausahaan, 2(6), 68-73. https://doi.org/10.24912/jmbk.v2i6.4910

Swari, N., \& Giantari, I. (2017). Peran kepuasan konsumen memediasi hubungan nilai utilitarian dan nilai hedonik dengan loyalitas konsumen. E-Jurnal Manajemen Universitas Udayana, 6(3), 1194-1220. https://ojs.unud.ac.id/index.php/Manajemen/article/view/26814/17917

Wang, Y., po lo, H., Chi, R., \& Yang, Y. (2004). An integrated framework for customer value and customer-relationship-management performance: A customer-based perspective from China. Managing Service Quality: An International Journal, 14(2/3), 169-182. https://doi.org/10.1108/09604520410528590 